\title{
Rousseau PaRa ALÉM De SI MESMO: NietzSCHe E O PERFIL PSICOLÓGICO DO ROUSSEAUÍSMO
}

\author{
[ROUSSEAU BEYOND ONESELF: NIETZSCHE AND THE PSYCHOLOGICAL PROFILE OF \\ ROUSSEAUISM]
}

\author{
Saulo Krieger * \\ Universidade Federal de São Paulo, Brasil
}

\begin{abstract}
Resumo: O objetivo do presente artigo é reabilitar e aprofundar um traço da relação entre Nietzsche e Rousseau que a pesquisa Nietzsche tem relegado, possivelmente por considerá-lo óbvio e crer que nada há a se dizer a respeito: Nietzsche crítico de Rousseau. Com isso, propomo-nos trazer à luz esse traço, mas evidenciando a esfera mesma que o filósofo alemão está a levar em conta em suas observações críticas: a esfera inconsciente, que segundo Nietzsche teria ditado os rumos da filosofia de Rousseau e do rousseauísmo. Nesse sentido, abordaremos o atentado à noção de alma por Descartes no século XVII, a crescente vulnerabilização dessa noção em razão da Revolução Científica dos séculos XVII e XVIII, e a reação de alguns luminares do XVIII ao que podemos referir por um desencantamento do mundo, a reação de Rousseau. Para Nietzsche, a reação de Rousseau, mais do que uma contribuição filosófica autônoma, seria uma reincidência do filósofo e de seus seguidores em dispositivos ancestrais de relação do homem com a natureza, como o de imaginar um passado áureo de deuses e heróis e o de imputar ao meio externo ameaças que visualiza dentro de si.
\end{abstract}

Palavras-chave: Iluminismo; Inconsciente; Alma; Cogito; Tipo
ABSTRACT: The main purpose of this article is to rehabilitate and deepen a feature of the relation between Nietzsche and Rousseau that has been relegated by the Nietzsche research, possibly by considering it obvious and by supposing that there is nothing more to say about, i. e., Nietzsche critic of Rousseau. Then, we propose to bring to light this feature, with an emphasis on the very scope the German philosopher is considering in his critical comments: the unconscious sphere, that gave directions to Rousseau's philosophy and to rousseauism. In this sense, we shall discuss the attack on the ancient notion of soul by Descartes in 17th century, the increasing weakening of this notion on account of the Scientific Revolution from 17th and 18th centuries, the reaction of some of 18th century representatives to what we may refer as a disenchantment of the world, the reaction of Rousseau. According to Nietzsche, the reaction of Rousseau, more than an autonomous philosophical contribution, would be an unconscious incidence of the the philosopher and his followers in ancestors devices of mannature relation, namely, figuring a Golden era in a past of gods and heroes and ascribing to external environment threats percieved as internal ones.

KEYWORDS: Iluminism; Unconscious; Soul; Cogito; Types 


\section{INTRODUÇão}

Tão óbvia é, ou parece ser, a atitude crítica de Nietzsche para com Rousseau, que os comentários de análise da relação entre eles têm sido quase unânimes em, indo no contrafluxo da "obviedade", contemplar seus pontos de contato. Uma verdadeira aversão, que em parte se justifica, à ideia de pensadores irreconciliáveis. De fato, há de se convir que os pontos em comum entre eles não são poucos, nem de pouco desdobramentos. Bem nessa direção, em obra de fôlego já se contemplou a relação entre eles com a intenção de inserir Nietzsche no pensamento político moderno; nessa chave, o autor do Emílio é contemplado como pensador-chave, adversário e antagonista, por certo, mas também como interlocutor que, ao intentar transfigurar a natureza humana imersa numa sociedade decadente, incita Nietzsche a pensar sua condição de filósofo e educador (cf. ANSELL-PEARSON, 1991, p. 18-23)1x. Outra contribuição foi bem-sucedida em apontar profícuas semelhanças entre os dois pensadores: ambos são pensadores da décadence e ambos se ocuparam profunda e criticamente da civilização em que estavam inseridos; ambos viram o quanto o homem estava a se distanciar de suas principais características naturais e a ressentir-se; ambos descortinaram a dinâmica em comum de ressentidos e sofredores, e constataram, ambos, o quanto o moralizar é um processo de vingança (cf. Viesenteiner, 2005)2x. Examinou-se, ainda, o quanto a atração de um e outro pela perspectiva da natureza vincula-os ao devir e à afirmação da vida; e viu-se, por fim, como cada qual afronta a tradição racionalista, apontando para outras forças à disposição do ser humano: um mesmo tom de certo exagero nas análises aqui como lá, uma aposta desmesurada em si mesmos e no seu modo de criticamente ver e fazer ver a sociedade e a modernidade (cf. Hardt, 2012, p. 207-218)3x.

Ante a perspicácia dessas contribuições, somos levados a pensar que eleger tema como "Nietzsche crítico de Rousseau" seria algo por demais simples, mesmo simplório, e anacrônico em face desse estado de coisas. Pensar "Nietzsche crítico de Rousseau" seria quase conceber uma relação unidimensional, tomar como valor de face a letra corrosiva e provocativa do primeiro com relação ao segundo, sem levar em conta o quanto ele oculta sua reverência e afinidade, o quanto se orgulha em se ombrear a figuras de incontornável relevo - como a Rousseau. Certo, mas será mesmo que tudo já foi dito e evidenciado sobre o Nietzsche crítico de Rousseau? Essa impressão pode ser apenas uma primeira impressão, ademais uma impressão sugestionada. E afinal de contas, pode-se dar um passo para fora dela e perguntar: será que a oposição NietzscheRousseau se esgota no que o autor do Zaratustra expressamente polemiza, não raro de modo estratégico e ardiloso, sim, contra a moralidade e a vulnerabilidade do autor do Emílio? De modo mais amplo, será ainda possível tematizar o Nietzsche tão-somente crítico de Rousseau, sem mas nem porém, e nem por isso ser rebarbativo ou simplista? Nós aqui apostamos que sim. E propomos que sim. No que segue, estamos a propor uma crítica de Nietzsche a Rousseau não a versar sobre questionamentos de ordem moral ou política, que é o viés predominante ao se tratar essa relação, mas contemplando o viés psicológico tão caro ao filósofo de Sils-Maria. Nós aqui propomos uma crítica a postar-se em estratos devidamente assumidos pela reflexão nietzschiana, ainda que recônditos, a pautar-se por dispositivos textuais reiteradamente acionados, ainda que bem pouco explorados.

\section{DA VIRAGEM CARTESIANA AO FENÔMENO ROUSSEAU}

Para muito além dos manuais de história da filosofia, Nietzsche nos permite pensar a movimentação que tornou possível a revolução cartesiana, a passagem do século XVII ao XVIII, e propriamente o ícone oitocentista Rousseau já de bem outra maneira. Um modo pelo qual se tem em mente não os caminhos expressa e reconhecidamente trilhados pela razão, e sim as dinâmicas que levaram essa mesma 
razão a trilhar este ou aquele caminho. De nossa parte, antes de fazer atentar para a dissonância entre a história da filosofia stricto sensu e a história da filosofia segundo o que poderíamos chamar de suas "pedras de tropeço" - isto é, a filosofia segundo Nietzsche - urge rememorar o salto teórico proporcionado pelo XVII em análise que, bastante breve, não destoaria de nenhuma das duas versões sobre o desenrolar filosófico - nem a dos manuais, nem a "outra", de Nietzsche.

Sabe-se que, com a viragem protagonizada por Descartes, o modo de posicionar questões em filosofia já não versaria sempre e em última instância sobre o que existe (ontologia) ou sobre uma hierarquização do que existe (metafísica), mas sim um e outro questionamento estariam subsumidos à matriz epistemológica, isto é, ao que um eu pensante pode efetivamente conhecer, ao modo como ele pode chegar a um conhecimento certo do mundo: a verdade sobre o mundo fazia-se assim dependente das certezas do sujeito que o conhece. A viragem cartesiana foi devidamente pavimentada pelo pitagorismo dos fundadores da nova ciência, de Copérnico a Galileu, para quem o procedimento matemático se justificaria em razão de a própria natureza ter estrutura matemática. Se se pode associar dessa maneira, inédita, a natureza a um produto da abstração de processos mentais, que são os números, estavam dados ambiente e coordenadas para se evidenciar a magnitude da consciência subjetiva no conhecimento da natureza... - como que a compensar a não centralidade do homem, a derrocada da visão de mundo que até então se tinha. Tudo se passa como se inconscientemente se ponderasse: ante a perplexidade pelo todo desvelado como indefinido, ou mesmo como infinito, procuro dominá-lo pelas minhas próprias abstrações, matemáticas, que não estão no mundo - estão em mim; a súbita imensidão, variedade e imprevisibilidade do mundo a todo tempo ricocheteiam em quem, afinal, está a percebê-lo e se contrapõe a ele; por tal fenômeno de rebote evidencia-se, como nunca antes, a figura de um eu, ou melhor, antes disso, a figura do cogito. Ato contínuo, esse eu a assomar-se por trás do cogito é também um limite, visto como um "fora do mundo"; ele é a fixidez outrora encontrada no próprio mundo, a fazer as vezes, do refúgio que o mundo já não propicia; em seu âmbito, ante a extensão e indeterminação do mundo, Descartes introduz uma dúvida que, se é radical e hiperbólica, é também encenada e controlada, resposta moderna e sobranceira ao mundo indefinidamente extenso: se duvido, com tudo isso desvela-se que é por meio desse eu, pensante, que duvida, que me posiciono diante do mundo, e pela metafísica e pelas outras ciências eu o poderei dominar.

A magnitude do refúgio inconsciente no cogito foi além das razões alegadas para tal, como foi além do próprio Descartes e mesmo do racionalismo. Do conhecer que significa tornar o pensante semelhante ao pensado, em Platão, da tese aristotélica pela qual o conhecimento em ato é o próprio objeto4x, o conhecer que necessariamente passa pelo cogito como postulado metodológico foi validado mesmo por filosofias que não o reconheceram de maneira expressa. Se o filosofar, então, doravante, de um modo ou de outro - racionalista, empirista, realista transcendental, idealista... - teria de necessariamente passar pela chancela do sujeito chamado à consciência, no decorrer do século XVII, e também no XVIII, sucederam-se tratados e ensaios que se destinavam a perscrutar, afinal de contas, o que pode esse sujeito pensante: o que pode, como o pode, até que ponto. Daí o Ensaio sobre o entendimento humano, de Locke; o Tratado da natureza humana, de Hume; os Princípios do conhecimento humano, de George Berkeley. Ao fim e ao cabo, evidentemente, Kant e o seu tribunal a julgar da possibilidade dos juízos sintéticos a priori, na Crítica da razão pura. Mas para além dessas preocupações estritamente epistemológicas, o XVIII é o século em que a árvore concebida e plantada no XVII vai efetivamente frutificar, capitaneada pela física, ainda que esta não seja bem a física cartesiana. E "frutificar" quase que poderia ser entendido no sentido literal, uma vez que novas, incipientes ciências, pautadas pelo método e pelo exemplo da física, germinam e já tendem a se encetar para fora do corpo filosófico. Se esse frutificar vai acabar por se vergar contra a própria metafísica, no século XIX, no XVIII tal ainda não acontece, e o que se tem é a crença no progresso e nas potencialidades humanas, sem - de nenhum modo, em nenhum nível - ainda se 
imaginar que tal possa produzir efeitos deletérios.

Aí se teria, em brevíssimo esboço, a passagem do século XVII ao XVIII segundo a visão corrente em filosofia. Para Nietzsche, porém, ao menos quando tem em mente não os caminhos expressamente trilhados pela razão, e sim as dinâmicas que a levaram $a$ trilhar por este ou por aquele caminho, a visão sobre a passagem do século

132 XVII ao XVIII é bem outra. Pela formulação que se tem em 9 [178], outono de 1887, “o século XVII é aristocrático, ordenador, altivo contra a animalidade, rigoroso contra o coração, não afetivo, chegando a ser sem afeto, 'não alemão', contraposto ao burlesco e ao natural, generalizador e soberano contra o passado: pois ele acredita em si." (NIETZSCHE, 1887, fragmento póstumo 9 [178])5x.

São traços evidenciados por Nietzsche não à medida que delineiam o trajeto expresso e deliberado da razão, mas segundo o modo como dão a entrever a atuação de forças inconscientes no íntimo dos filósofos, como que a traçar de antemão os caminhos da filosofia nesses três séculos. Nisso, se o século XVII é por ele associado ao aristocratismo, como o XIX o será à animalidade, o XVIII é referido pela prevalência do feminino e identificado sobretudo a Rousseau e à sua influência.

Antes de mais nada, entendemos que, em Nietzsche, a mulher e o feminino não devem ser tomados como valor de face, mas como dispositivo linguístico a fazer referência a modos tipificados de reação a estímulos do mundo. Tanto que o próprio Rousseau é associado ao feminino. E "reação" é algo aqui a se realçar, afinal de contas se trata de um modo meramente negativo de interagir com o meio circundante. Em Crepúsculo dos ídolos, Nietzsche afirma que "as épocas devem ser medidas conforme suas forças positivas", ocasião em que ressalta o Renascimento como "última grande época" (cf. NIETZSCHE, 1888\2006, p. 87). Quanto ao século XVII, como acima se viu o filósofo o associa a um aristocratismo, uma vez que um dos traços da ideia do aristocrático em Nietzsche está na primazia do sentimento de seu próprio valor e dignidade, num sentimento de autoconfiança. Pela sua autoconfiança, isto é, confiança no homem, no poder da razão e em suas conquistas vindouras, também o XVII teria sido propelido predominantemente por forças afirmativas e positivas.

Entretanto, na passagem do XVIII para o XVIII, o que era aristocrático se plebeizou, com o progresso e a disseminação das ideias democráticas. Com isso, as rédeas passaram a ser tomadas pelos sentimentos negativos, reativos, com uma intensa valorização de ideais e virtudes gregárias, que, como Nietzsche observa, "são provocadas por nossa fraqueza" (cf. NIETZSCHE, 1888\2006, p. 87). E eis que, em se tratando de propalar tais ideias e virtudes, Rousseau lhe aparece como a figura mais influente, mesmo irradiadora - para a Revolução Francesa, para o romantismo e mesmo indo ao encontro do "espírito alemão". Rousseau é antecipador e visionário: nele a "substância propriamente revolucionária" torna-se "corpo e alma" (cf. NIETZSCHE, $1880 \backslash 2008$, p. 266) já antes da Revolução Francesa. Mas Rousseau é também a "desrazão" da Revolução (cf. NIETZSCHE, 1881, fragmento póstumo 15 [37]), a Revolução em seu viés mais virulento, pois sua influência, que veremos subterrânea e desencadeadora, impediu que o Iluminismo viesse a transformar costumes, instituições e indivíduos de maneira lenta (cf. NIETZSCHE, 1880\2008, p. 266). Rousseau, enfim, é mais do que Rousseau, à medida que encarna e enceta um movimento em âmbito europeu: "Não se pode negar que desde o início do século passado, uma corrente de redespertar moral atravessa a Europa. Somente então a virtude voltou a ser eloquente [...] Se procurarmos as fontes dessa corrente, encontramos Rousseau; mas o Rousseau mítico, que foi inventado segundo a impressão de suas obras" (cf. NIETZSCHE, 1880/2008, p. 263).

Para fazê-lo, o Rousseau "mais do que Rousseau", ainda que não de todo deliberadamente, teve de seduzir. E como sedutor, o Rousseau mítico foi o da libertação das mulheres, dos escravos, dos pobres e dos trabalhadores (cf. NIETZSCHE, 1884, fragmento póstumo 25 [178]). O grau de sua sedução pode estar relacionado a seu fanatismo: Rousseau é o "fanático moral" (cf. NIETZSCHE, 1887, fragmento póstumo 9 [3]). Seu poder de sedução está na percepção inconsciente de uma certa demanda de 
seu tempo, e essa percepção é convertida em meio de sedução por meio de ação subreptícia: é o que instila no romantismo, por antecipação, o anseio de vingança (cf. NIETZSCHE, 1888/2006, p. 64). Para tanto, se desde Descartes o mergulho no que paulatinamente virá a ser uma subjetividade se faz filtro e chancela para se aperceber do mundo, Rousseau dele se vale para se aperceber de sua própria natureza: e o caso é que ele se percebe como sendo mau (cf. NIETZSCHE, 1881, 2004, p. 251) e miserável (cf. NIETZSCHE, 1886, fragmento póstumo 9 [146]). E por ter se percebido como mau, a profundidade de seu mergulho, se o fez falar aos seus, acabou por onerar sua própria natureza - e por descompensá-lo como pensador. Para Nietzsche, juntamente com Schopenhauer Rousseau é aquele que se transborda: é o gênio cuja reflexão, em "seus instantes mais fecundos, seus voos para o alto e para longe" está em doloroso descompasso com sua constituição e de algum modo excede a sua força (cf. NIETZSCHE, 1881/2004, p. 538).

Ora, até aqui vimos que se alegaram radicalidades e fecundidades entre os dois filósofos, e tantos atributos ao autor do Emílio, alguns aparentemente contraditórios, e um Rousseau que vai além de seus escritos, que percebe seu tempo melhor do que todos e antes que todos o percebam, um Rousseau que, ademais, antecipa o tempo que está a germinar, que o apressa, que não vê com bons olhos tendências de seu próprio tempo, que transborda a sua própria condição e excede o que pode suportar... E isso tudo, afinal, porque da profundidade a que desceu não pôde contemplar com bons olhos a si mesmo. Se a história da filosofia costuma ter em Rousseau aquele que julga seu tempo, a sociedade de seu tempo como má, corruptora e corrompida, Nietzsche parece ir mais longe, ou talvez trilhar caminhos incertos, ao apostar que Rousseau, possivelmente antes de imputar julgamentos à sociedade, vira a sua própria natureza como má. Ora, dissemos antes de julgar seu tempo, sua sociedade como má e corrompida? Seu julgamento seria então obra de uma reatividade? Não por acaso, para Nietzsche o século XVIII, "século de Rousseau" (cf. NIETZSCHE, 1887, fragmentos póstumos 9 [131] e 10 [2]), seria todo ele sentimento e exaltação, uma miríade de sentimentos confusos e atitudes contraditórias, basicamente como reação ao que se encetara no século XVII, e que ali agora dava seus bons e maus frutos. O século XVIII seria, na verdade um conjunto de reações desencontradas (cf. NIETZSCHE, 1887, fragmentos póstumos 9 [178])6x, a ponto de ser, para o autor do Zaratustra, mais uma reação a seus próprios feitos, e aos do século XVII, do que seus próprios feitos. Seria em grande parte uma reação ao próprio Iluminismo que protagonizou. Afinal de contas, os tais feitos indiretamente diriam respeito ao estatuto da condição humana, podendo não se revelar favoráveis à imagem que até então o homem tinha de si. Não por acaso, o próprio Rousseau radical e fecundo, que não se cabe em sua própria constituição, o Rousseau "além de Rousseau” é, por excelência, reação.

\section{O FEITO ILUMINISTA E SEUS DESCONTENTES}

Se no âmbito da história da filosofia tradicional tanto já se disse e fez ver sobre o Iluminismo, sobre o quanto as luzes iluministas deram seguimento ao processo desencadeado pela revolução científica dos séculos XVI e XVII, no contexto nietzschiano a inteira ênfase recai sobre o papel das ações inconscientes em filosofia7x. Essas ações exercem seu desapercebido trabalho em duas frentes: (1) nos efeitos colaterais e compensatórios do colapso da crença em Deus, irrefletidamente sopesados por um recrudescimento da moral (cf. NIETZSCHE, 1878/2000, p. 33; 1887, fragmento p9 [143] e 10 [163]; 1888/2006, p. 65); (2) nos efeitos colaterais e erosivos da substituição da concepção de alma como se tinha no sentido antigo ou cristão, que é suspensa pela dúvida cartesiana e sucedida pelo fluxo de pensamentos sobre o mundo e pela capacidade de conhecer (cf. NIETZSCHE, 1886/1999, p. 58). Se já referimos que o anseio de Descartes por uma árvore do conhecimento vingou sem que a física-tronco dessa árvore fosse a física cartesiana, convém agora descer ao detalhe da árvore do 
conhecimento tal como efetivamente se expandiu, para então apreender seus desdobramentos reativos e inconscientes, na literatura, na poesia... e em Rousseau.

Ainda no século XVII, os cartesianos buscaram elucidar todo e qualquer fenômeno físico pela ação mecânica dos corpos em contato. Fenômenos como luz, eletricidade, magnetismo eram explicados com base em partículas de diferentes formas 134 e tamanhos, havendo também a recorrência ingênua a algo como "matérias sutis" (cf. BURNS, 2003, p. 46). Porém esse modelo não resistiu à ascensão de outro, de maior densidade mensuratória e matematicamente mais rigoroso, que foi o de Newton: diga-se a esse respeito, que, se a gravidade, como força quantificável, mas de atuação a distância, parecia reavivar "qualidades ocultas" do aristotelismo, além de conter aspectos teológicos - devidamente denunciados pelos cartesianos -, nem mesmo esses ecos, aparentemente regressivos, impediram que a teoria newtoniana prevalecesse. Derrotando as variações todas em torno do estrito mecanicismo cartesiano, a física newtoniana prevaleceu em função do rigor e do urdimento de fenômenos naturais que sua matematicidade proporcionava8x.

Entretanto, já em sua aplicação a animais e plantas o pensamento mecanicista da tradição cartesiana teve efeito mais duradouro do que a sua aplicação aos fenômenos celestes. Com o espírito sendo restringindo ao próprio homem e a Deus - e este, ainda assim, como um insípido garante epistemológico da boa corrrespondencialidade entre res cogitans e res extensa -, a interpretação cartesiana de animais e plantas ao modo de máquinas - e se máquinas, desprovidas de espírito - poderia bem ser estendida ao ser humano por filósofos predipostos a negar o conceito de alma até mesmo no homem afinal de contas, segundo Nietzsche a partir de Descartes a alma de fato se fizera algo mais rarefeito, dispositivo secundário e reativo em relação ao pensar (cf. NIETZSCHE, 1886/1999, p. 58)9x: aliada ao mecanicismo, a disseminação dessa concepção foi um ensejo para que na França surgisse o materialismo de Julien Offroy de La Mettrie (1709-1751), a conceber o corpo como sistema material e mecânico - logo, desprovido de alma. Esse quadro ensejou também Claude Adrien Helvétius (1715-1771), pensador abertamente ateu, com sua concepção do ser humano como criatura material, e não espiritual (cf. BURNS, 2003, p. 94).

Ato contínuo, a explicação divina, ou que permitisse conotação religiosa ou justificação transcendente - era o caso de Newton -, ficava mais e mais distante, mesmo relegada, para toda uma série de fenômenos naturais. Uma série de substituições dava-se de forma gradual e disseminada. A doutrina dos humores, de Galeno, que dominara a medicina medieval e a Renascença, era substituída pela medicina mecanicista de Herman Boerhaave (1668-1638) (cf. BURNS, 2003, p. 13). Ao longo do século XVIII, as pretensões alquímicas de se descobrir um solvente universal e a pedra filosofal pouco a pouco foi assimilada ao charlatanismo e ao ocultismo, com seus procedimentos e vocabulário sendo absorvidos por uma ciência, a química, e suas pretensões econômicas já se direcionando a uma indústria química - o caso mais emblemático foi o de Johann Friedrich Böttger (1682-1719), que migrou do malogro da conversão em ouro para um bem-sucedido fabrico da porcelana (cf. BURNS, 2003, p. 54). Na astronomia, o triunfo da compreensão dos movimentos planetários por Newton demandou o aperfeiçoamento e resolução de problemas em mecânica planetária, realizados por uma série de cientistas, sobretudo os da escola francesa de Maupertuis (1698-1759), de Clairaut (1713-1765), D’Alembert (1717-1783), Lagrange (17361813), Laplace (1749-1827), e do suíço Leonhardt Euler (1707-1783) (cf. BURNS, 2003, p. 10). O nível de aprofundamento e especificidade mal permitiria lembrar que apenas no século anterior, o XVII, a astronomia efetivamente se livrara da crendice astrológica. E a botânica se viu transformada pela ideia de que, sim, as plantas se reproduziam sexualmente, e a tal se chegou mediante o contato com um número crescente de espécies até então desconhecidas na Europa (cf. BURNS, 2003, p. 36); passando-se do montante de espécies à organização desse cabedal, a revolução na área se completava com a ascensão de esquemas classificatórios, que não raro rivalizavam entre si (cf. BURNS, 2003, p. 36). Ao assim referirmos esses campos que se encetavam 
como ciências - sem nenhuma pretensão à objetividade, diga-se -, observe-se ainda que para todas essas mudanças a invenção e disseminação de aparelhos como termômetros, microscópios, telescópios, fez-se providencial: isto significa, mais observação - e mensuração - em dimensões até então imperscrutadas, menos espaço para a imaginação e a fantasia. O que acima já referimos como "estatuto da condição humana" definitivamente demandaria uma reacomodação. O mesmo vale para uma certa concepção da natureza, mas de uma natureza que não poderia ser dominada ou mensurada. Estava preparado o terreno para uma reação.

Sim, por certo que havia vozes dissonantes em meio a esses e outros avanços em tantas novas áreas. Na Inglaterra, a desconfiança romântica em relação à ciência, aos cientistas e seus experimentos se eternizaria no Frankenstein, obra de 1818 de Mary Shelley (cf. BURNS, 2003, p. 172). Antes disso, porém, o poeta William Blake (17571827), não poupava nem a eminência de John Locke, nem mesmo a unanimidade Isaac Newton, culpando-os pela redução de Deus a um mero relojoeiro, e pela redução da inteira glória e maravilha do universo à matemática e à mecânica (cf. BURNS, 2003, p. 248). Já no continente europeu, a antecipar as vozes românticas contra o Iluminismo, Rousseau fez as vezes de uma reação filosoficamente articulada. É sabido que em seu Discurso sobre as artes e ciências, que apresentou por ocasião do prêmio oferecido pela Academia de Dijon, o filósofo argumentou que o progresso das ciências não fazia os homens mais felizes, e sim os corrompia e afastava da natureza. São fatos e traços rousseauistas já bem conhecidos e assimilados pela história da filosofia, e para além dela. A esse respeito, contudo, o olhar de Nietzsche tem algo de mais invasivo e mais abrangente, a revelar, talvez, uma dimensão não exclusiva a Rousseau, e sim compartilhada, e por ele em todo caso encetada. Já não se tratará propriamente de Rousseau, mas do fenômeno rousseauista, cujo poder de perscrutação e irradiação remete a um quadro mais oculto e insidioso.

\section{ROUSSEAU REATIVO}

A ideia de progresso é filha do século XVIII. No curso da história, tanto civilizações avançadas quanto sociedades tribais simplesmente desconheciam a ideia de que o futuro seria melhor que o presente e o passado1x0x. Mais ainda, acalentavam a ideia de que o futuro seria uma repetição do passado e do presente. Para a maioria das culturas humanas, a era dourada fora aquela em que se acreditava que os ancestrais tinham falado diretamente com Deus e realizado feitos heroicos; isso era o ensejo para que de bom grado aceitassem tradições e valores tais quais se lhes apresentavam. Aos olhos dos homens, portanto, "bom" era dar continuidade ao que assim recebiam, "bom" era agir e pensar na esfera mesma daquela visão de mundo (cf. NIETZSCHE, $1882 / 2011$, p. 57), com os padrões, regras e expectativas tendo assim sido fixados num passado remoto ou imemorial. Seguir tais regras e satisfazer tais expectativas não lhes demandava esforço especial, afinal de contas elas os faziam ser quem eram, tal qual se mostravam e se compreendiam. Era uma visão de mundo que não comportava margens a franquear a concepção de um futuro melhor que o presente, nem a de um contínuo aperfeiçoamento das condições de vida, nem a de que a mudança pudesse ser algo bom.

Nesse contexto, quanto aos modos de o ser humano interagir com o mundo que o cerca, a remissão a um passado áureo seria a regra, e a iluminista crença no progresso, a novidade. Com isso é-se levado a pensar que a recorrência a um passado áureo na busca por sentido e orientação seria um traço da natureza humana, melhor dizendo1x1x, de um certo tipo humano1x $2 \mathrm{x}$ em suas interações com o mundo. E assim é preciso bem ponderar a afirmação do autor do Zaratustra, para quem Rousseau, "quando [ele] lamenta a corrupção e degeneração da sociedade como triste consequência da cultura, isso tem por base uma experiência pessoal" (cf. NIETZSCHE, 1878/2012, p. 260-261). É preciso ter cautela quanto ao "pessoal" de tal experiência. Talvez não fosse "pessoal" no sentido que via de regra lhe é associado, ou seja, de um "pessoal" passível de ser 
remetido a decepções amorosas ou frustrações profissionais ou acadêmicas. Não se trata do pessoal casual e "pequeno". O "pessoal" que nesse caso interessa a Nietzsche seria o "pessoal" replicável, passível de reincidência, referido como "pessoal" por ser o ressurgimento de um tipo humano num meio em que ele já não era predominante, em razão da sua reação peculiar em meio ao generalizado otimismo quanto ao avanço das 136 artes e ciências, e ao progresso da inteira civilização. Seria na verdade um "pessoal" compartilhado por todo um tipo humano predominante antes do século XVIII, ou talvez do XVII, que durante todo aquele tempo foi o tipo, isto é, a modalidade por excelência de se interagir com o mundo. Fez-se menos preponderante, com a revolução científica e com o Iluminismo, mas no próprio século iluminista voltou a irromper, precisamente em sensibilidades como a de Rousseau. E Rousseau, por não estar sozinho em suas fraquezas e em seus vícios (cf. NIETZSCHE, 1878/2012, p. 260-261), conquistou muitos adeptos.

Pois as "fraquezas, lacunas e vícios" (cf. NIETZSCHE, 1878/2012, p. 260-261) de Rousseau teriam adubado o seu talento que era bem o de atavicamente perceber modos de relação com a natureza dos primórdios da humanidade, e neles reincidir, reavivando-os. No século de Rousseau, contudo, não havia uma ancestralidade heroica para a seu lastro se remeter pela via direta, positiva e compartilhada, que um dia fora a da crença de toda uma cultura. O que um dia fora o traço heroico de ancestrais imaginários converte-se no "bom" da natureza boa; o que era o contato direto com os deuses vem a ser o contato com sua própria natureza, idealizada como a condição do homem primevo e naturalmente bom. Desse modo, o que um dia fora uma crença compartilhada, criada pelos estratos profundos da alma, faz-se em Rousseau, e com Rousseau, abstração teórica, hipótese filosófica reativamente articulada. Em um caso como no outro se tem a inconsciente remissão a uma origem hipotética, que valorizaria a sua própria constituição, percebida como frágil à luz de ameaças.

"Frágil à luz das ameaças". Justamente, quando se entra na questão do sentir-se ameaçado, e nas reações a tal sensação, está-se falando na tendência de todo um tipo humano. Além da primeira inclinação aqui arrolada, pela qual se imaginava um passado heroico, com ancestrais que viam a face de Deus, há outra, ainda mais profunda e igualmente compartilhada pelo homem durante muito tempo, em tempos imemoriais. Pois também a essa tendência Rousseau, no século XVIII, emprestou envergadura filosófica: a propensão a se evadir do que em nós parece pernicioso, e imaginar-se à parte do que em nós parece caprichoso e mal, o que se dá mediante a projeção dessa característica em algo à nossa volta. Esta já é expressamente referida pelo fílósofo alemão:

Primeiro os homens projetaram-se na natureza: em toda parte viram a si mesmos e a seus iguais, isto é, suas características más e caprichosas, como se estivessem escondidas entre nuvens, temporais, animais de rapina, árvores e plantas: naquele tempo inventaram a "natureza má". Depois veio a época em que novamente se imaginaram fora da natureza, a época de Rousseau: estavam tão fartos uns dos outros, que quiseram possuir um canto a que não chegasse o homem e seu tormento: inventaram a "natureza boa". (cf. NIETZSCHE 1881/2008, p. 24)

A reger a interação entre homem e natureza existem liames, como que tonalidades, passíveis de ser entendidos sob diferentes formulações. A depender da formulação, tal liame pode ser o de um simulacro, como se tem em Platão - a alma como simulacro do mundo -, como pode ser o de um espelhamento e representação, como a partir de Descartes. Mas esse liame pode ser o que em última instância se pauta pela ameaça (como se lê em Sobre verdade e mentira no sentido extramoral) e pela necessidade (como se lê no aforismo 354 d'A gaia ciência), e isto significa, justamente, que o homem percebe do mundo sobretudo o que o ameaça. À medida que, pela via instintual, ele não meramente contempla o mundo, mas com ele se interpenetra, a ameaça ou a necessidade é percebida, e devidamente introjetada, ou seja, é projetada para dentro. Ora, configurando-se assim esse vínculo, por que não se daria o mesmo 
processo em sentido inverso, com o mau que é percebido dentro a se projetar para fora? Nesse sentido, uma característica "má e caprichosa" (cf. NIETZSCHE 1881/2008, p. 24) - uma ameaça interna e já não externa - igualmente acabará por instaurar um vínculo intenso, mesmo uma clivagem, entre homem e natureza, desta vez ao modo de uma projeção propriamente dita. Seja um perigo ou um incômodo de caráter externo ou interno, ato contínuo - e irrefletido - a ordem é livrar-se dele, e se tal não pode ser pela força, pode ser por um processo de atribuição semântica, a contornar o incômodo por meio de um ardillx3x ou, ainda, encontrando em si mesmo um refúgio. Para esse último caso, a ameaça interna deve ser lançada, projetada, imputada ao meio exterior: pode ser projetada para "nuvens, temporais, aves de rapina" (cf. NIETZSCHE 1881/2008, p. 24), como para o homem tribal ou de civilizações antigas; ou então pode ser projetada no convívio social, na civilização e no progresso, como se tem em Rousseau.

\section{A SEDUÇÃo ROUSSEAUISTA}

O que o autor do Emílio teria visto em si para, tal qual o homem de priscas eras, tentar extirpar dali o que interpretava como sendo mau? Nietzsche o dá a entender em mais um aforismo de Aurora: ao olhar para si, Rousseau teria visto "“apenas o solitário e 'mau', exclamou Diderot: ao que logo sentiu-se aquele mortalmente ofendido. Por conseguinte, admitiu para si mesmo que Diderot estava certo" (cf. NIETZSCHE 1881/2008, p. 251). E na sequência, explica por que motivo, afinal, o mal martiriza: "de fato, no meio da sociedade e das relações, toda inclinação má tem de restringir-se tanto, pôr tantas máscaras, deitar-se tão frequentemente no leito de Procusto da virtude, que bem se poderia falar de um martírio do homem mau" (cf. NIETZSCHE 1881/2008, p. 251). Note-se que Nietzsche aí se refere às condições para que o mau fosse tomado como mau, mas sem fazer referência ao que Rousseau teria visto em si como sendo mau. O que então seria "mau" para a sociedade em sua necessária invocação e exigência de tantas máscaras, de sua bitola de virtudes? Justamente o que está por trás das máscaras, que tem de ser ocultado ou ao menos domado para bem da vida em sociedade: o sexual, o agressivo, o egoísta e irrefletido, e isto significa, a animalidade pulsante em cada um de nós. Essa animalidade só pode ser considerada "má" pelo filtro da sociedade a operar mediante castrações e travestimentos. Rousseau, possivelmente como poucos homens em seu tempo, estava em estreito contato com os sucedâneos de uma animalidade reprimida, como a vingança, a frustração, a inveja. E sim, pode-se imaginar que o espetáculo não seria nada agradável. Viu-se como mau, horrorizou-se ou, pelo menos, desconfiou de si. Dessa demente desconfiança adveio, aliás, sua megalomania (cf. NIETZSCHE, 1882-1883, fragmento póstumo 5 [1]) - como a de poder encarnar docilmente em si a natureza. Assim, de seu autodesprezo, de sua vaidade intensificada adveio o seu filosofar, ao modo de um sintoma (cf. NIETZSCHE, 1886, fragmento póstumo 9 [146]) - e não como posição refletida e consciente. Com isso acabou por seduzir outros que em seu tempo compartilhavam do mesmo anseio, que afinal não eram poucos, e disso o movimento romântico viria a ser a mais cabal comprovação.

Assim, de fanático moral a animal desvelado, quem seria mesmo o Rousseau sedutor? De que modo seduziria? Na obra publicada, fica claro que Nietzsche associa a "corrente de redespertar moral [que] atravessa a Europa" (cf. NIETZSCHE, 1880/2008, p. 263) à sua fonte irradiadora, que seria precisamente o autor do Emílio. Se já referimos que Rousseau vai além de Rousseau, não se trata ali do Rousseau pessoa, mas do Rousseau mítico. Ao que tudo indica, para Nietzsche o fílósofo suíço teria captado e dado forma a um sentimento latente que então havia e vicejaria um tanto mais. Foi perceptivo a ponto de com certa profundidade sondar não apenas a si, mas o ambiente cultural à sua volta. A sensibilidade aliada a uma evidente vulnerabilidade, não era apenas sua. Quanto a essa condição vulnerável, está relacionada a uma posição a que o 
homem cartesiano e kantiano se restringiu. Em referência a Descartes e Kant, vimos que Nietzsche observa que toda a filosofia moderna procedera a "um atentado contra o velho conceito de alma" (cf. NIETZSCHE, 1886/1999, p. 58). E mencionamos que quando Descartes sujeita o que antes era alma a um "penso", mais do que questioná-la ou negá-la, sem mais a faz submergir sob toda uma torrente de pensamentos (cf., acima,

138 "O feito iluminista e seus descontentes". Em seu propósito de radical contraposição à Escolástica - para a qual, seguindo a tradição aristotélica, a alma "é a forma substancial do corpo" -, Descartes inaugura nova tradição, na qual a alma deixa de ter qualquer papel nas funções básicas da vida e é instância secundária em relação aos pensamentos. De modo sintomático, a palavra anima aparece uma vez na Segunda Meditação, para então ser rechaçada por não resistir à dúvida hiperbólica, dando lugar à palavra mens (mente).

Se a vulnerabilidade é assim filha de Descartes e de seu século, a vulnerabilidade de uma alma convertida em mente e deixada a descoberto não se fez o garrote que se faria no século de Rousseau. No século XVII, a rarefação e subjugação do que um dia fora a ideia de alma era devidamente compensada pela confiança na razão, pela esperança em seus feitos e na solidez da metafísica. Com o Iluminismo, porém, e com o desdobramento da philosophice naturalis em variados e vigorosos campos científicos, ao fim e ao cabo o que restava do conceito de alma poderia bem ser varrido, por exemplo, por um materialismo francês que negava toda a realidade espiritual e reduzia o universo à matéria, com mesmo a moral humana podendo ser reduzida a uma base fisiológica (cf. BURNS, 2003, p. 154). Se apenas materialistas radicais desejavam banir de todo a visão religiosa do mundo (cf. BURNS, 2003, p. xvii), o fato é que o gradual travejamento do mundo e de seus fenômenos por explicações calcadas em observações e classificações empíricas foi paulatinamente minando o espaço para Deus, para a fé cristã e para a própria alma. Tudo se passa como se Rousseau tivesse padecido sob esses ataques, a golpear alma e Deus. Tudo se passa como se houvesse aí um padecimento compartilhado e compassivo que o autor do Emílio tivesse captado em seu tempo, a ele aderido, convertendo-se em sua voz filosófica mais articulada. Isso explicaria seu poder de irradiação, que seria menos um contágio superficial e mais o compartilhamento de uma tendência. De um cristianismo combalido, ele agarrou-se às franjas morais e democráticas, possivelmente mais resistentes: daí "sua preferência pelos pobres, pelas mulheres, pelo povo como soberano", pela qual, segundo o autor d'A gaia ciência, pôs-se "num movimento inteiramente cristão" (cf. NIETZSCHE, 1884, fragmento póstumo 25 [130]).

Ocorre que Rousseau não apenas revigorou um tipo de homem, captou um "estado de espírito" remanescente em seu tempo, como obviamente foi por ele captado. Sem mais defesas ou senso crítico, fez-se lhe sujeito, interpretando mal uma fina percepção de sua própria condição, que seria, enfim, a de um animal enjaulado pela sociedade. Não se permitiu chegar à assimilação de sua própria animalidade, tomando a sua natureza como apenas e simplesmente má. Se, a exemplo de Descartes, de Spinoza - e o mesmo se terá com Kant ou Schopenhauer - foi interceptado pela moral, por um certo ar de seu tempo e filosoficamente se fez aquém do que poderia ter sido, nem por isso, à visão de Nietzsche, deixou de ser generoso com a filosofia. A ela se consagrou inteiro, sacrificando a vida, como fará também Schopenhauer (cf. NIETZSCHE, $1881 / 2008$, p. 236). Mas isso não significa tê-la vivenciado profundamente, e, aliás, vivência e protagonização no ato mesmo de filosofar só se farão realidade com a filosofia do próprio Nietzsche.

\section{REFERÊNCIAS}

ANSELL PEARSON, K. Nietzsche contra Rousseau. A study of Nietzsche's Moral and Political Thought. Cambridge: Cambridge University Press, 1991.

BURNS, W. E. Science in the Enlightenment. An Encyclopaedia. Santa Barbara CA: ABC Clio, 
2003.

CHAUÍ, M. "Um anacronismo interessante". In: Martins, A., Santiago, H. \& Oliva L. C. As ilusões do eu. Spinoza e Nietzsche. Rio de Janeiro: Civilização Brasileira, 2011, p. 323348.

HARDT, L. S. "Rousseau e Nietzsche: de como a ideia da natureza estabelece o devir". In: Cadernos de ética e filosofia política, n. 21 (2012): Rousseau: Natureza e Sociedade, p. 207- 218.

KRIEGER, S. "Um olhar de Nietzsche ao século XVII: os subterrâneos da revolução cartesiana". In: Cadernos Nietzsche, vol. 39. n. 3, 2018,

NIETZSCHE, F. Sämtliche Werke - Kritische Studienausgabe (KSA). Edição organizada por Giorgio Colli e Mazzino Montinari. Berlim: De Gruyter \& Co., 1988, 15 vols.

NIETZSCHE, F. A gaia ciência. Trad. Paulo César de Souza. São Paulo: Companhia das Letras, 2011.

NIETZSCHE, F. Além do bem e do mal. Trad. Paulo César de Souza. São Paulo: Companhia das Letras, 1999.

NIETZSCHE, F. Aurora. Trad. Paulo César de Souza. São Paulo: Companhia das Letras, 2008.

NIETZSCHE, F. Crepúsculo dos ídolos. Trad. Paulo César de Souza. São Paulo: Companhia das Letras, 2010.

NIETZSCHE, F. Humano, demasiado humano. Trad. Paulo César de Souza. Trad. Paulo César de Souza. São Paulo: Companhia das Letras, 2012.

NIETZSCHE, F. O andarilho e sua sombra (Humano, demasiado humano II). Trad. Paulo César de Souza. São Paulo: Companhia das Letras, 2008.

VIESENTEINER, J. L. "Algumas refutações sobre a crítica de Nietzsche a Rousseau”. In: Anais do II Colóquio Rousseau, Instituto de Filosofia e Ciências Humanas - IFCH, Unicamp.

Notas

1 Cf. ANSELL-PEARSON, K. Nietzsche contra Rousseau. A study of Nietzsche's Moral and Political Thought. Cambridge: Cambridge University Press, 1991.

2 Cf. VIESENTEINER, J. L. "Algumas refutações sobre a crítica de Nietzsche a Rousseau". In: Anais do II Colóquio Rousseau, Instituto de Filosofia e Ciências Humanas - IFCH, Unicamp.

3 Cf. HARDT, L. S. "Rousseau e Nietzsche: de como a ideia da natureza estabelece o devir". In: Cadernos de ética e filosofia política, n. 21 (2012): Rousseau: Natureza e Sociedade, p. 207- 218 .

4 Por mais que a identidade entre cognoscente e conhecido tenha conhecido restrições, como pela espécie, forma que determina o ser da coisa, em São Tomás de Aquino.

5 Para todas as ocorrências dos fragmentos póstumos de autoria de Nietzsche, referidos segundo a dupla numeração classificatória de Colli \& Montinari, $<\mathrm{http}$ //www.nietzschesource.org/\#eKGWB $>$

6 "O século XVIII é dominado pela mulher, exaltado, espirituoso, superficial, mas com um espírito a serviço da exaltação, do coração, libertino no usufruto da espiritualidade, solapador de toda autoridade; ébrio, feliz, claro, humano, falso diante de si, no fundo muito canalha [viel Canaille au fond], social..." (fragmento póstumo 9 [178], novembro de 1887).

7 Bem entendido, com "ações inconscientes" fazemos referência aqui não a conteúdos mentais desapercebidos, que, não obstante, compõem o quadro percebido, ao modo das petites perceptions de Leibniz; nem a conteúdos latentes, no sentido de desativados, sem ação. Referimo-nos, isto sim, a dispositivos mentais atuantes na mente de filósofos em função dos tipos humanos por eles encarnados. Não obstante não serem percebidos, como tampouco são pessoais e intransferíveis, são determinantes de suas "escolhas" racionais e filosóficas, mesmo das que se revelam as mais consequentes.

8 Não obstante, em Newton ainda havia espaço para explicações religiosas dos fenômenos naturais particulares remetendo-os ao plano providencial de Deus. O modelo newtoniano de fato reservava um papel a Deus como mantenedor do sistema solar e como retificador das irregularidades dos movimentos planetários. Com a mecânica celestial de PierreSimon Laplace, porém, o sistema solar se deu a demonstrar como um todo, isto é, considerado em todas as suas regularidades, a intervenção divina já não sendo necessária (cf. BURNS, 2003, p. 131, 158, 189). 
9 "Desde Descartes - e antes apesar dele do que a partir de seu precedente - todos os filósofos têm feito um atentado contra o velho conceito de alma, sob a aparência de uma crítica ao conceito de sujeito e predicado - ou seja: um atentado contra o pressuposto fundamental da doutrina cristã" (cf. Nietzsche, Além do bem e do mal, p. 58).

10 Note-se que aqui não se está a incluir as civilizações cristãs, para as quais o passado era o pecado e o mal, o presente, a redenção e o futuro, a salvação, numa estrutura e num modo de pensar que se propagou no Ocidente - sua cultura e seus pensadores - para além das estritas fronteiras da religião cristã. Mas mesmo no âmbito de tais civilizações cristãs tampouco se concebia um futuro melhor no tocante ao progresso material.

11 Introduzimos e corrigimos deliberadamente a noção de "natureza humana" para fazer atentar ao fato de que para Nietzsche não se tem natureza humana ou espécie humana: "natureza humana" deveria ser uma expressão proibida por uma questão de rigor filosófico (cf. NIETZSCHE, 1880, fragmento póstumo 6 [150]), da mesma forma que "homem" é um conceito simplificado (cf. NIETZSCHE, 1872 - 1873, fragmento póstumo 19 [236]), e assim como o filósofo dirá, ao final de sua produção, que a humanidade propriamente dita não existe (cf. NIETZSCHE, 1888, fragmento póstumo 15 [8]). O conceito de humanidade, assim como "Estado, povo, [humanidade], processo do mundo" são "conceitos gerais abstratos", cuja "divinização", segundo Nietzsche, apresenta a "desvantagem de diminuir o fardo do indivíduo e de aliviar sua responsabilidade" (cf. NIETZSCHE, 1873, fragmento póstumo 29 [74]). Assim, se se pode falar em "humanidade", "homem", "espécie humana" de maneira funcional, não é o caso de "divinizar" tais conceitos - como, de resto, nenhum conceito ou palavra em se tratando do universo nietzschiano. Se não há "espécie humana", o que há são tipos, que envolvem o processo de identificação de traços comuns a indivíduos ou a culturas variadas - daí a teoria dos tipos, sobre a qual se assenta, juntamente com a noção de valor, o problema da cultura sobre o pano de fundo das teorias da evolução do século XIX.

12 A noção de tipo é crucial para se compreender certas dinâmicas do pensamento de Nietzsche, e de seu entrelaçamento com as de valor e a de cultivo resulta o problema que lhe é central e irradiador - o da cultura. Tipo, ou tipologia, é ideia estreitamente relacionada à de cultivo ou disciplina do homem. Se, como ressaltamos na nota acima, essa problematização filosófica se dá sobre o pano de fundo científico das teorias da evolução natural, o cultivo da besta-homem se espraia ao longo de gerações o tipo se forma com equivalente lentidão, já que depende de valorações extensivamente inculcadas em povos e indivíduos, e que assim neles se cristalizam. De tal maneira é lento o processo de maturação, que o tipo homem, como se tem no aforismo 62 de Para além de bem e mal, é ainda um animal sem uma configuração definitiva - e com isso, com o cultivo do animal homem no seio de uma cultura, tangenciamos a preocupação por excelência de Nietzsche, a própria justificação de sua filosofia. Deve-se observar que, nessa noção, à diferença dos dispositivos conceituais com que se está habituado em filosofia, não se tem fixidez, nem imobilidade, nem univocidade, já que a tipologia se pauta pelo estudo das diferenças, variantes e possibilidades de variação inerentes ao homem, a grupos de homens e a culturas, incluindo as suas morais, e isso sem que os processos de identificação de traços recorrentes se façam excludentes: um tipo não exclui a possibilidade de outras características, ou de transformações - e as características e transformações, por sua vez, remetem à ideia de cultivo. Nesse mesmo sentido, de flexibilidade e multivocidade, um indivíduo, como uma cultura ou uma moral, pode pertencer a diferentes tipos.

13 A referência aqui é à conversão da necessidade de comunicação em capacidade de comunicação, como se tem no aforismo 354 d'A gaia ciência: "ele precisava, sendo o animal mais ameaçado, de ajuda, proteção, precisava de seus iguais, tinha de saber exprimir seu apuro e fazer-se compreensível". 